Cíntia Moreira de Menezes, Tatiane Alvarenga Sanchez, Fabiana Oliveira Alves

\title{
RELATO DE EXPERIÊNCIA DE UM PROGRAMA DE HUMANIZAÇÃO AO COLABORADOR E A ESTRATÉGIA DE INTRODUÇÃO DE MINDFULNESS EM UM HOSPITAL PÚBLICO
}

Eixo temático:

Introdução: O Mindfulness pode ser definido como um "estado ou traço que se refere à capacidade de estar atento ao que acontece no presente, com abertura e aceitação", e tem se mostrado eficaz, no tratamento da síndrome burnout (esgotamento profissional - decorrente de estresse prolongado no ambiente de trabalho) e prevenção de estresse. A introdução de conhecimentos teóricos e vivências práticas baseadas em Mindfulness guia-nos a um novo paradigma em busca de medidas preventivas e de promoção de saúde aos colaboradores, atuando em termos da chamada "prevenção primária".

Objetivo: Descrever a estratégia para implementação de Mindfulness no ambiente de trabalho..

Método: Relato de experiência da implantação de programa de cuidado ao colaborador usando a técnica do Mindfulness. Foram coletados dados dos colaboradores de um hospital de grande porte, que participaram espontaneamente das vivências de Mindfulness nos meses de agosto e outubro de 2018. Os colaboradores foram convidados a participar por meio de anúncio no sistema interno e comunicação dos gestores As teorias e técnicas utilizadas foram: Técnica dos 3 Passos, Primeiro e Segundo Sofrimento, Técnica da Caminhada e do Movimento com Atenção Plena e Técnica da Respiração.

Resultado: Participaram espontaneamente 98 colaboradores do programa de humanização e cuidado do colaborador, destes, $72 \%$ (70) colaboradores de enfermagem, sendo $17 \%$ (16) Enfermeiros, 55\% (54) Técnicos e Auxiliares de enfermagem, dos colaboradores das áreas de apoio participaram 28\% (27) e a média de tempo de vivência de Mindfulness por colaborador foi de 84 minutos.

Conclusão: A proposta do programa de humanização e cuidado do colaborador nesta primeira etapa, foi proporcionar vivências e aproximar a teoria e conceito de Mindfulness, como ferramenta de auto cuidado e gestão emocional através do auto conhecimento e inteligência emocional, para posteriormente na segunda etapa, ser introduzido o programa de Mindfulness-Based Health Promotion - MBHP.

REFERÊNCIAS:CEBOLLA, Ausiás.; DEMARZO, Marcelo. O que é mindfulness?.In: CEBOLLA, Ausiás;CAMPAYO, Javier García;, DEMARZO, Marcelo (orgs.). Mindfulness e Ciência: da tradição à modernidade. São Paulo: Palas Athena, 2016 